\title{
Therapeutic Potential of Bone Marrow-Derived Mesenchymal Stem Cells on Experimental Liver Injury Induced by Schistosoma mansoni: A Histological Study
}

\author{
Heba Fikry, Sara Abdel Gawad, Walaa Baher
}

Department of Histology, Faculty of Medicine, Ain Shams University, Cairo, Egypt

\begin{abstract}
Background and Objectives: Bone marrow derived mesenchymal stem cells (BM-MSCs) have been proposed as effective treatment of many diseases owing to their unique ability to differentiate into other cell types in vivo. Schistosoma mansoni (S. mansomi) infection is characterized by hepatic granuloma formation around schistosome eggs at acute stage of infection, followed by hepatic fibrosis at chronic and advanced stages. Whether BM-MSCs have an ameliorative effect on hepatic tissue injury caused by $S$. mansoni infection or not, was inspected in the current study.

Materials and Results: Female Swiss Albino mice were divided into a control group and an experimental group. Half of control animals served as donors for bone marrow stem cells, and the other half was used to collect liver samples. Experimental group was injected with circariae of $S$. mansoni, and then subdivided into three subgroups; Subgroup B1, sacrificed after eight weeks of infection without treatment, subgroup B2, received BM-MSCs at the eighth week and sacrificed four weeks later, and subgroup B3, was untreated till the twelfth week of infection. Histological examination of liver samples showed the formation of granulomas and liver fibrosis which were extensive in subgroup B3. However, treated subgroup illustrated improvement of liver histology, signs of hepatocytes regeneration, and possible contribution of oval cell in the process of hepatic and biliary regeneration.

Conclusion: BM-MSCs decreased liver fibrosis and contributed to an increase in oval cells, generation of new hepatocytes and/or to the improvement of resident hepatocytes in S. mansoni infected mice.
\end{abstract}

Keywords: S. mansoni, Mesenchymal stem cells, Liver fibrosis, Oval cells

\section{Introduction}

Schistosomiasis is a widespread parasitic infective disease that remains endemic in many countries. Despite major advances in control and substantial decreases in mor-

\footnotetext{
Accepted for publication December 23, 2015, Published online May 30, 2016 Correspondence to Walaa Baher

Department of Histology, Faculty of Medicine, Ain Shams University, Abasyia, Cairo 11358, Egypt

Tel: +20-1002050563, Fax: +20-222909854

E-mail: walaabaher78@gmail.com

(c) This is an open-access article distributed under the terms of the Creative Commons Attribution Non-Commercial License (http://creativecommons.org/ licenses/by-nc/4.0/), which permits unrestricted non-commercial use, distribution, and reproduction in any medium, provided the original work is properly cited.
}

bidity and mortality, schistosomiasis continues to spread to new geographic areas (1). One of the experimental models of hepatic fibrosis used to elucidate the mechanism involved in fibrogenic process is chronic infection with Schistosoma mansoni (S. mansoni) (2). The most commonly used therapeutic drug is praziquantel (PZQ), which has demonstrated efficacy in both prevention of some types of schistosoma infection and substantial reduction of worm burden in infected patients (3). Though, some reports established resistance to PZQ the mainstay of medical treatment (4), besides, the hepatic fibrosis caused by schistosomiasis is not eliminated by PZQ and has remained a clinical challenge (5). Hence, it is of great significance to explore new therapeutic approaches to ameliorate the damages caused by fibrogenesis in chronic liver disease (6). 
Mesenchymal stem cells (MSCs) have recently emerged as an effective advance to treat a variety of diseases with minimal invasive procedures and few complications (7). MSCs are multipotent cells that are capable of differentiating into functional hepatocytes, which have been effective in regenerating liver structure and promoting recovery of liver function (8). Thus, it is worthy to explore the possible role of MSCs in ameliorating liver damage caused by schistosomiasis.

\section{Study design}

50 Female Swiss Albino mice, 7 weeks old, weighing about $25 \mathrm{gm}$ were housed at the Schistosome Biological Material Supply Center of Theodor Bilharz Research Institute (TBRI), Giza, Egypt and treated in accordance with the valid International Guidelines for animal experimentation. Animals were classified into group A (control group, $\mathrm{n}=20$ ) and group $\mathrm{B}$ (experimental group, $\mathrm{n}=30$ ). Animals in group A were equally subdivided into subgroup $A_{1}(n=10)$ which served as donors for stem cells obtained from their bone marrow, and subgroup $\mathrm{A}_{2}$ $(\mathrm{n}=10)$ which were injected with phosphate buffer saline (PBS) and used to collect control liver samples. Whereas, animals in group B, were all infected with $S$. mansoni cercariae (60/mouse) (obtained from infected Biomphalaria alexandrina snails which were bred and maintained at the TBRI) injected subcautaneously, then subdivided into three subgroups; subgroup $B_{1}(n=10)$ sacrificed after eight weeks, subgroup $B_{2}(n=10)$ treated with $2 \times 10^{6}$ MSCs suspended in PBS per mouse at eighth week after infection then scarified four weeks later, and subgroup $B_{3}(n=10)$ allowed to survive for twelve weeks without treatment then sacrificed.

Infection was assured by finding $S$. mansoni eggs in stool 42 days post infection.

\section{Preparation and isolation of BM-MSCs for intraperitoneal administration}

Bone marrow cells were harvested by flushing the tibiae and femurs of mice in subgroup $A_{1}$ with Dulbecco's modified Eagle's medium (DMEM) supplemented with 10\% fetal bovine serum (FBS) - purchased from Lonza company, Swiss-, washed in PBS, resuspended in complete media supplemented with $1 \%$ penicillin-streptomycin, seeded in culture dishes, and incubated at $37^{\circ} \mathrm{C}$ in $5 \%$ humidified $\mathrm{CO}_{2}$ for $2 \sim 3$ days or upon formation of large colonies. When large colonies developed (80 90\% confluence), cultures were washed twice with PBS and the cells were detached using $0.25 \%$ trypsin in $1 \mathrm{mM}$ EDTA for $5 \mathrm{~min}$ at $37^{\circ} \mathrm{C}$. The suspension then centrifuged, viable and non- viable cells were counted using hemocytometer, followed by subculturing viable cells at $4 \times 10^{3}$ cells $/ \mathrm{cm}^{2}$, and used for experiments after the third passage.

BM-MSCS in culture were characterized by their adhesiveness and fusiform shape (Fig. 1A and 1B). Also, immune-histochemical detection of CD44 as a marker for BM-MSCS was done (Fig. 1C). Further characterization was performed by incubating BM-MSCS in osteogenic media for 21 days and detection of mineralized matrix deposition using alizarin red stain (Fig. 1D) (9).

\section{Fluorescence labelling for In Vivo Tracking of BM-MSCs (10)}

BM-MSCs were labelled using the PKH26 red fluorescence cell linker kit (Sigma Aldrich, USA) according to the manufacturer's protocol. In brief, subconfluent MSC after the third passage were detached and washed three times with serum-free medium. Cells were re-suspended at $1 \times 10^{7}$ cells in $1 \mathrm{ml}$ of diluent $\mathrm{C}$ plus dye, followed by incubation at $25^{\circ} \mathrm{C}$ for $5 \mathrm{~min}$. To stop the reaction, $2 \mathrm{ml}$ of FBS was added. Cells were supplemented with $4 \mathrm{ml}$ of complete medium and washed three times. Cells were resuspended at $1 \times 10^{6}$ cells in complete medium and used within $30 \mathrm{~min}$. For assessment of vitality and preservation of differentiation capacity of PKH26-labeled MSCs, they were reseeded onto plates and then underwent differentiation testing upon reaching confluence. For testing viability of PKH26-labeled primary BM-MSCs, they were re-cultured. Fluorescent microscope examination of liver specimens of mice treated with the labeled cells (subgroup $\mathrm{B}_{2}$ ) was done to insure their incorporation into liver tissue (Fig. 6A).

\section{Histological and immune-histochemical studies}

For light microscopic examination; liver samples were fixed in $10 \%$ buffered formalin, dehydrated, cleared and embedded in paraffin. Serial $5 \mu \mathrm{m}$ sections of the right lobes of the livers were stained with hematoxylin and eosin (H\&E), Masson's trichrome stain and immune-histochemical staining for cytokeratin 7 (CK7).

For transmission electron microscope (TEM) examination; small liver specimens $\left(1 \mathrm{~mm}^{3}\right)$ were fixed in $2.5 \%$ gluteraldhyde solution, followed by $1 \%$ osmium tetroxide, dehydrated and embedded in epoxy resin. Ultrathin sections were collected on copper grids and stained with uranyl acetate and lead citrate. Finally the sections were examined and photographed under a Jeol TEM 1200 Ex.

\section{Morphometric measurements}

Area percentage of collagen content using Masson's tri- 
chrome stain, the circumference of granulomatous lesion and the mean number of CK7 positive cells were measured in randomly chosen five fields/ section in five sections for every rat in each group at magnification 400 .

\section{Statistical analysis}

The measured parameters in the different subgroups were compared with each other using the statistical package for the social sciences (SPSS) computer program analysis for variance (ANOVA)-one way analysis and post-Hoc least significant difference (LSD). Differences were considered significant when the $\mathrm{p}$ value was $\leq 0.05$. Summary of the data was expressed as mean \pm standard deviation (SD).
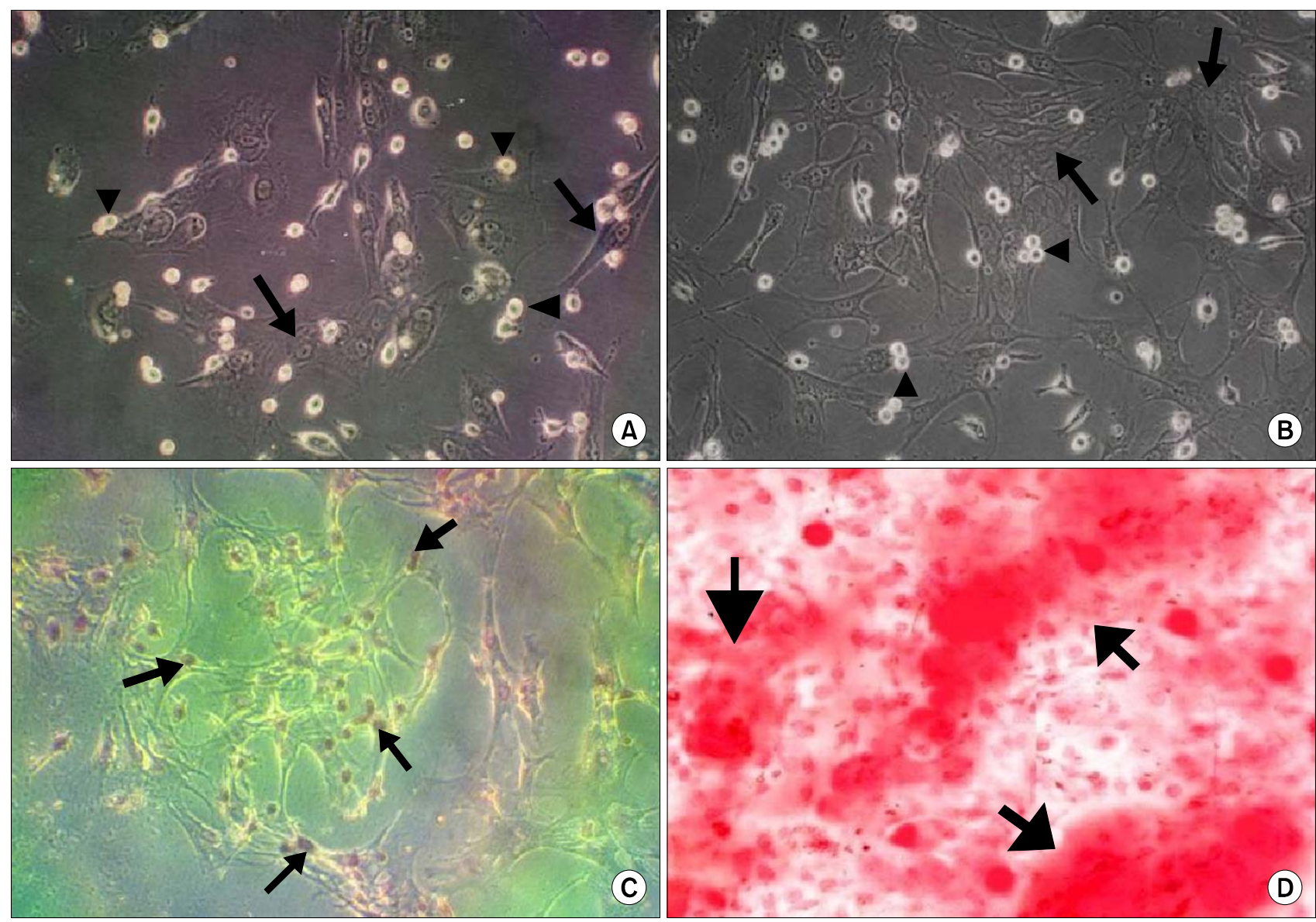

Fig. 1. (A) Culture on day five, showing adherent fibroblast like cells with multiple processes. They have granular cytoplasm and vesicular nuclei. Some nuclei appear with two nucleoli $(\uparrow)$. The non-adherent cells appear rounded and refractile $(\Delta)$. (B) Culture on day nine, showing confluent dense homogenous fibroblast like cells with granular cytoplasm and multiple interdigitating process ( $\uparrow$ ). Notice the presence of few rounded and refractile non-adherent cells $(\Delta)$. (C) Streptavidin-biotin peroxidase staining for CD44 showing that most of the cultured cells exhibit positive brownish reaction for CD44 ( $\uparrow$ ). (D) BM-MSCs incubated in osteogenic media for three weeks stained with Alizarin red. Red staining $(\uparrow)$ demonstrates mineralised matrix produced by osteoblastic differentiation (phase contrast microscope X200).

\section{Results}

\section{Light microscope examination}

Examination of $\mathrm{H} \& \mathrm{E}$ stained sections of the control group revealed intact classical hepatic lobules with plates of hepatocytes radiating from the central vein separated after injection with circariae) few small bilharizial graulomas were seen around bilharizial ova, sparing part of the liver tissue inbetween them (Fig. 2B). In subgroup $B_{2}$ (treated group) the granulomatous lesions decreased both in number and size sparing wider areas of the liver tissue (Fig. 2C), also, many small oval cells having oval nuclei and deeply stained cytoplasm were seen along the periphery of the granulomatous lesions (Fig. 3A). In the same by blood sinusoids (Fig. 2A). In subgroup $\mathrm{B}_{1}$ (eight weeks 

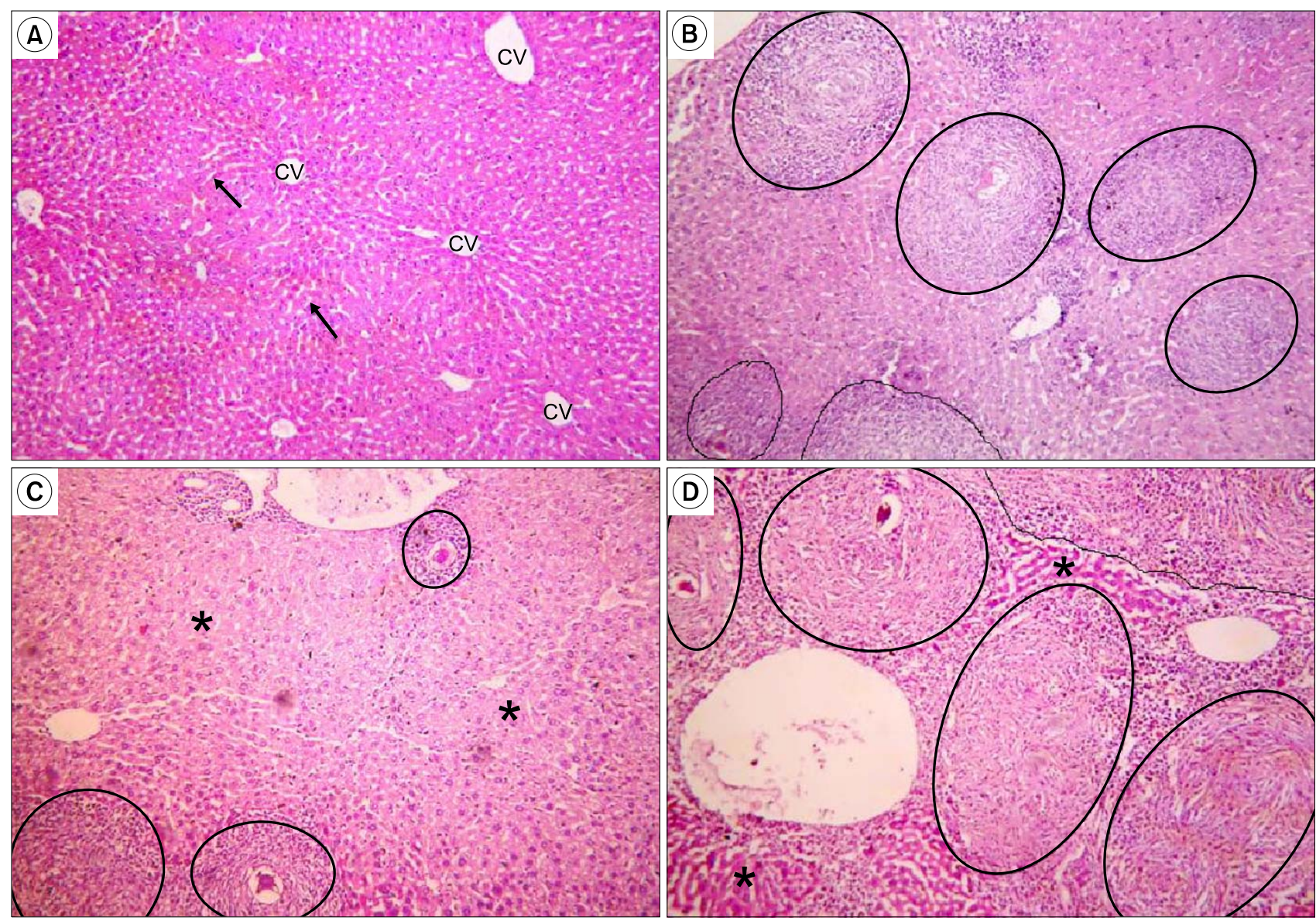

Fig. 2. (A) Show classical hepatic lobules with plates of hepatocytes radiating from the central vein (cv) separated by blood sinusoids ( $\uparrow$ ) (Control, H\&E $\times 160$ ). (B) Show many scattered bilharizial granulomas around S.mansoni eggs (circumscribed areas) (Subgroup B1, H\&E $\times 160$ ). (C) Show small few bilharizial granulomas (circumscribed areas) with normal hepatic tissue inbetween $(*)$ (Subgroup B2, H\&E $\times 160$ ). (D) Show many large bilharizial granulomas (circumscribed areas) occupying most of hepatic tissue sparing only few areas of hepatocytes (*) (Subgroup B3, H\&E ×160).

group, bile ducts appeared almost intact and were lined with columnar epithelium (Fig. 3C). On the contrary, in the untreated group sacrificed 12 weeks after circariae injection (Subgroup $\mathrm{B}_{3}$ ); the granulomatous lesions were profuse and large, with only narrow liver tissue appear inbetween them (Fig. 2D), oval cells were almost absent (Fig. 3B) and bile ducts were distorted with vacuolated epithelium (Fig. 3D).

In Masson's trichrome stained sections, few collagen fibers were observed in the control group around the central veins and portal areas (Fig. 4A). In subgroup $\mathrm{B}_{1}$, an increase in the amount of collagen fibers was noted in the granulomatous lesions (Fig. 4B), whereas in subgroup $\mathrm{B}_{2}$, the amount of collagen fibers in the graulomatous lesions were markedly decreased (Fig. 4C). In subgroup $\mathrm{B}_{3}$, the granulomatous lesions were almost replaced with collagen fibers with bridging fibrosis between them occupying most of the liver tissue (Fig. 4D).

Liver sections immunohistochemically stained for CK7; showed few CK7 positive cells lining the bile ducts and around them in the control group (Fig. 5A). In subgroup $B_{1}$, only very few $C K 7$ positive cells were detected along the periphery of the granulomatous lesions (Fig. 5B), in contrast, $\mathrm{CK} 7$ positive cells were very numerous around the granulomatous lesions in subgroup $\mathrm{B}_{2}$ (Fig, 5C). In the untreated group (subgroup $\mathrm{B}_{3}$ ) the CK7 positive cells were few (Fig. 5D).

\section{Electron microscopic examination}

Ultra-thin sections of liver specimens of the control group showed that hepatocytes had large rounded, central vesicular nucleus with the usual characteristic chromatin distribution. The cytoplasm illustrated numerous mitochondria, rough endoplasmic reticulum (rER), and gly- 

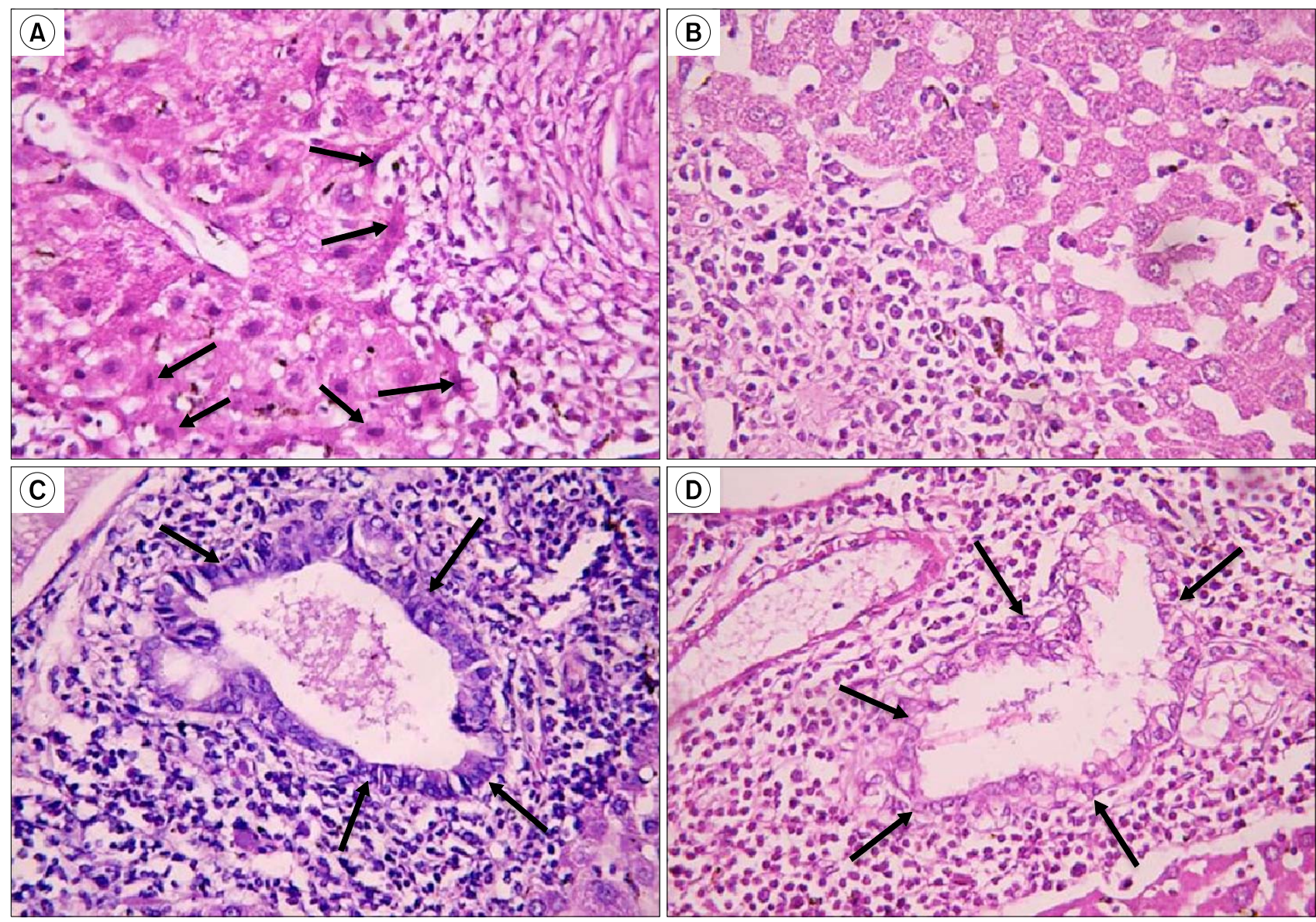

Fig. 3. (A) Show cells with small oval shaped centrally located nuclei along the periphery of the granulomatous lesions ( $\downarrow$ ) (Subgroup B2, H\&E $\times 640$ ). (B) Small oval shaped cells are absent around granulomatous lesions (Subgroup B3, H\&E $\times 640$ ). (C) Show proliferating hepatic duct lined with columnar cells having basal nuclei $(\downarrow)$ (Subgroup B2, H\&E $\times 640$ ). (D) Show bile duct with disintegrated and highly vacuolated epithelium $(\downarrow)$ (Subgroup B3, H\&E $\times 640$ ).

cogen rosettes (Fig. 6B). Moreover, few microvilli of the hepatocytes were projecting into the space of Disse, hepatocytes stellate cells (HSCs) were seen in the perisinusoidal space with many fat droplets in their cytoplasm and bile canaliculi appeared with microvilli projecting into them (Fig. 6C). In subgroup $\mathrm{B}_{1}$, hepatocytes were necrotic, their nuclei showed abnormal chromatin distribution, the bile canaliculi illustrated partial loss of microvilli, and an increase in the amount of collagen fibers was noticed. Eosinophils appeared in the blood sinusoids with their characteristic granules (Fig. 6D). Hepatocytes in Subgroup $\mathrm{B}_{2}$ were premature with signs of regeneration in the form of irregular nuclear membrane and an increase of organelles e.g. mitochondria, $\mathrm{rER}$ and free ribosomes (Fig. 7A). Microvilli that project in the space of Disse and in bile canaliculi were almost as in the control group (Fig. 7B). In subgroup $\mathrm{B}_{3}$, collagen fibers were abundant and HSCs were detected in the perisinusoidal space, also, hepatocytes showed features of necrosis, and bile canaliculi illustrated partial loss of microvilli (Fig. 7C\&D).

\section{Morphometric \& statistical results}

The highest peaks of collagen area percentage were measured in untreated mice (subgroups $B_{1}$ and $B_{3}$ ). There was a significant reduction in the area percentage in control animals and in subgroup $B_{2}$ as compared to those in subgroups $B_{1}$ and $B_{3}(p=0.000$ and $p=0.000)$, although subgroup $B_{2}$ recorded a significant increase $(p=0.018)$ as compared to that in control mice (Table 1).

The mean number of CK7 positive cells / HPFs reached its highest peaks and showed a significant increase in treated rats that received BM-MSCs (subgroup $B_{2}$ ) when compared to control group, subgroups $B_{1} \&$ subgroup $B_{3}$. On the other hand, a non-significant difference $(p=0.648)$ was measured in subgroup $B_{1}$ as compared to that in sub- 

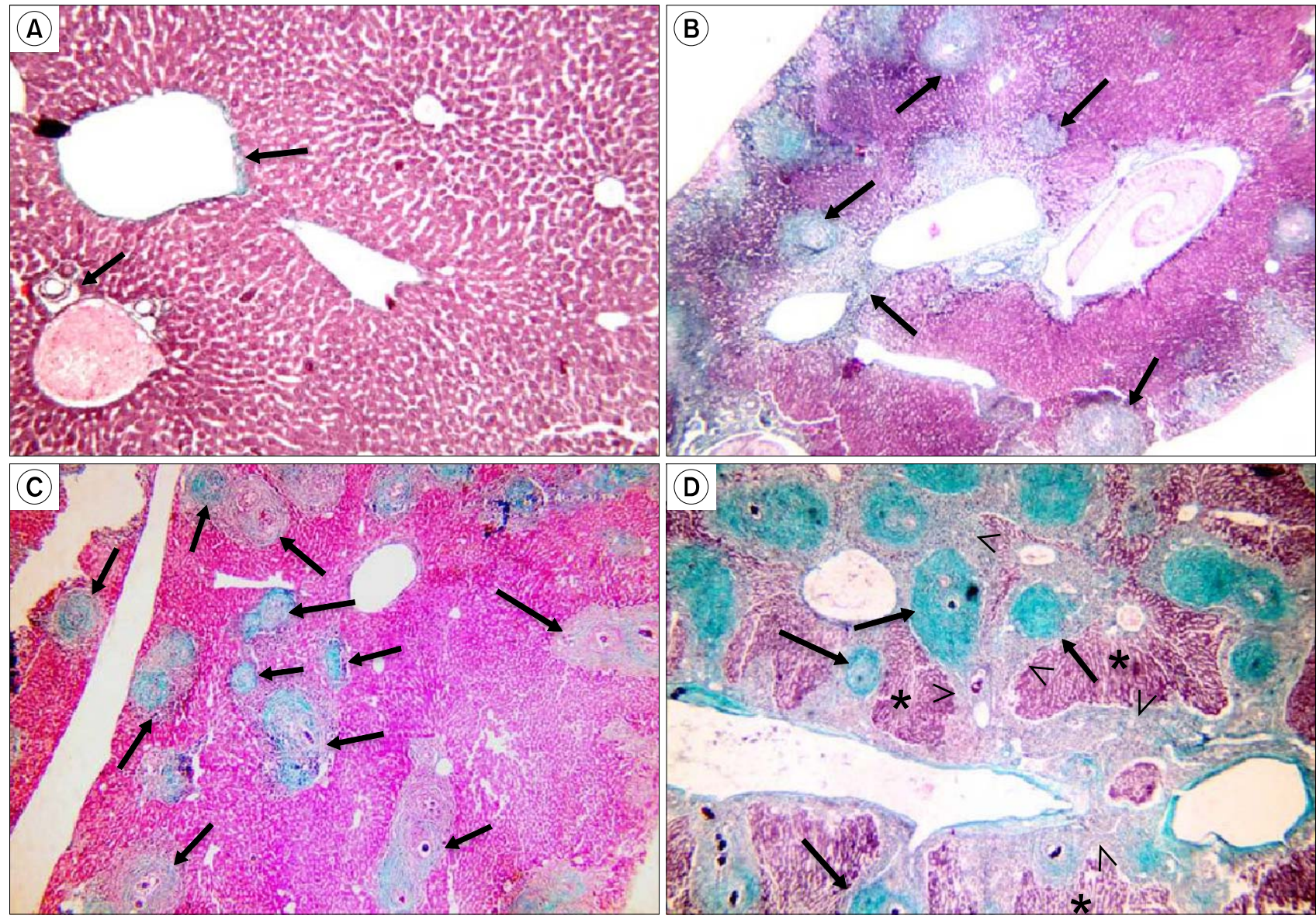

Fig. 4. (A) Show few collagen fibers around central veins and portal areas $(\uparrow)$ (Control, Masson's trichrome $\times 160$ ). (B) Collagen fibers are seen in granulomatous lesions $(\uparrow)$ (Subgroup B1, Masson's trichrome $\times 160$ ). (C) Few collagen fibers are present in granulomatous lesions ( $\uparrow$ ) sparing most of the hepatic tissue (Subgroup B2, Masson's trichrome $\times 160$ ). (D) Abundant collagen fibers occupy granulomatous lesions $(\uparrow)$ and form bridging fibrosis inbetween them $(<)$, sparing only few areas of hepatic tissue $\left(^{*}\right.$ ) (Subgroup B3, Masson's trichrome $\mathrm{x} 160)$.

group $\mathrm{B}_{3}$ (Table 1).

The mean granuloma circumference reached its highest peaks in subgroup B3 and measured a significant increase $(\mathrm{p}=0.000)$ as compared to subgroups $\mathrm{B}_{1}$ and $\mathrm{B}_{2}$. On the other hand, treated subgroup $B_{2}$, measured the least circumference and a significant decrease $(p=0.000)$ in the granuloma circumference was determined as compared to the other experimental untreated subgroups $B_{1}$ and $B_{3}$ (Table 1).

\section{Discussion}

Schistosomiasis is one of the most widespread parasitic infestations. The main pathology in S. mansoni infection is the formation of granulomas around eggs trapped in the portal venules of liver tissue (11). The eggs release a variety of substances that lead to antigen -specific humoral and cell mediated immune responses (12) which terminates in fibrosis and portal hypertension (13).

The notion that injured tissues secrete chemotactic factors to recruit MSCs and the numbers of MSCs homing to the liver is independent of the route of infusion (14), supported our conception of the beneficial role of MSCs as a therapy to recover organ structure. Thus, the aim of the present study was to assess the ameliorative potential of MSCs in S. mansoni induced liver damage.

Ghanem et al. (13), demonstrated that fibrosis developed during the chronic phase of granulomatous inflammation in murine schistosomiasis represent a protective function by isolating egg antigens that can potentially damage host tissues. In our study, the extent of fibrosis was estimated by the quantitative morphometric analysis of the collagen content in Masson's trichrome stained liver sections and granuloma area. The results re- 

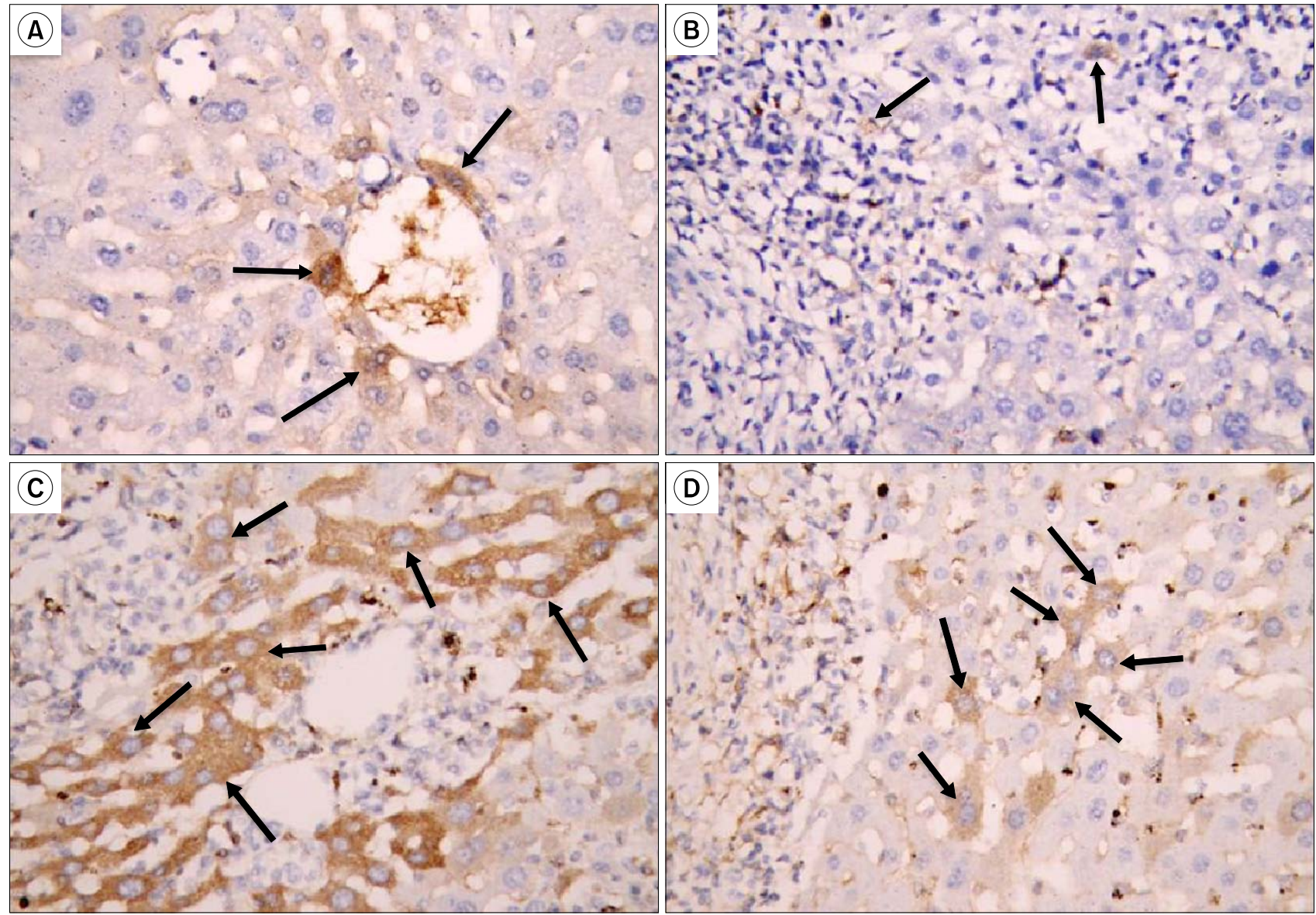

Fig. 5. (A) Show few CK7 positive cells lining and around a bile duct $(\uparrow)$ (Control, immunostaining for CK7 $\times 640$ ). (B) Very few CK7 positive cells along the periphery of granulomatous lesions $(\uparrow)$ (Subgroup B1, immunostaining for CK7 $\times 640$ ). (C) Many CK7 positive cells are seen along the periphery of granulomatous lesions ( $\uparrow$ ) (Subgroup B2, immunostaining for CK7 $\times 640$ ). (D) Few CK7 positive cells are seen near a granulomatous lesion $(\uparrow$ ) (Subgroup B3, immunostaining for CK7 $\times 640$ ).

vealed significant decrease in the collagen content after treatment with BM-MSCs.

One of the main mediators involved on fibrosis deposition during hepatic injury is transforming growth factor $\beta$ (TGF- $\beta$ ) (15). This cytokine stimulates the transition of stellate cells to myofibroblasts, which secrete high amounts of extracellular matrix and inhibit its degradation (16). TGF- $\beta$ levels were lowered after BM-MSC therapy in livers of $S$. mansoni-infected mice, reaching levels close to those found in normal mice (2). A decrease in TGF- $\beta$ production was also observed by Fang et al. (17), after therapy using BM-MSCs in mice with liver injury caused by CCl4 administration.

On the other hand, Rygiel et al. (18), reported that liver fibrosis is mainly due to accumulation of myofibroblasts, which may result from activation and proliferation of resident epithelial cells, including hepatocytes and bile duct cells, via epithelial-mesenchymal transition. In the current work; the decrease in liver fibrosis after treatment with BM-MSCs could be explained by the inactivation of HSCs by BM-MSCs, which is consistent with Pulavendran et al. (19), findings which indicated that BM-MSCs can inhibit the activation of HSCs and induce apoptosis to relieve fibrosis. On the contrary, El-Mahdi et al. (20), stated that the anti-fibrotic effect of BM-MSCs may be related to an enhancement of collagen degradation rather than a decrease in collagen synthesis.

Liver stem cells, termed oval cells in rodents (21) proliferate under certain pathological conditions, when hepatocyte proliferation is prevented by severe liver injury (22). Oval cells, named for their morphological appearance, are bipotent precursor cells that can differentiate into bile duct cells (23) and hepatocytes (24). Oval cells originate from the terminal branches of the intrahepatic biliary system, the canals of Hering (25) or next to bile ducts (26). Hepatic oval cells and cholangiocytes but not normal 

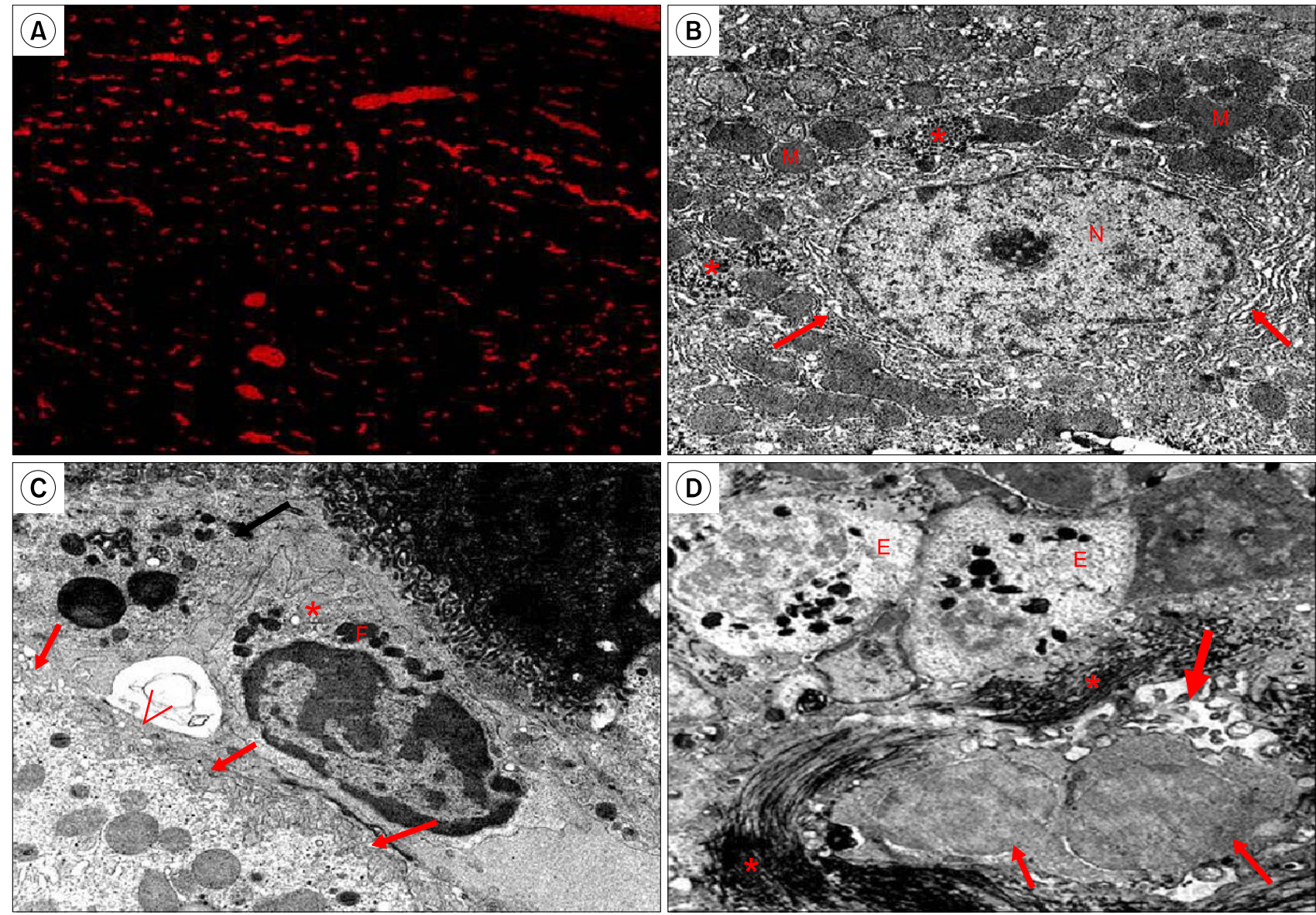

Fig. 6. (A) PKH26- labeled MSCs are seen scattered in the liver tissue of treated group (fluorescent microscope, Subgroup B2). (B) Show a hepatocyte with large rounded, central vesicular nucleus $(\mathrm{N})$. The nucleus shows the usual characteristic chromatin distribution. The cytoplasm contains numerous mitochondria $(M)$, rER $(\uparrow)$, and glycogen rosettes $(*)$ (Control, TEM $\times 10000)$. (C) Show part of a hepatocyte with few microvilli projecting from the surface facing the space of Disse $(\uparrow), \operatorname{HSCs}(*)$ are seen in the perisinusoidal space with many fat droplets (F) in the cytoplasm. A bile canaliculus appears in the form of its microvilli $(<)$ (Control, TEM $\times 10000$ ). (D) Show an increase of collagen fibers $(*)$ in between necrotic hepatocytes that have abnormal distribution of nuclear chromatin ( $\uparrow$ ), damage of a bile canaliculus in the form of partial loss of its microvilli (thick $\uparrow$ ). Eosinophil cells (E) appear in the blood sinusoids with their specific granules (Subgroup B1, TEM $\times 8000$ ).

hepatocytes express CK7 (27).

In the present study, many small young oval cells exhibiting small oval shaped centrally located nuclei were present along the periphery of the granulomatous lesions confirmed by immune-histochemical staining for CK7 in MSCs treated subgroup. Also, marked proliferation of bile ductules, and signs of mature hepatocytes regeneration were detected in electron microscopic specimens in the same subgroup. These findings were not detected in the untreated subgroup.

All these previous findings strongly suggest the valuable role of MSCs in liver remodeling following Schistosomiasis induced liver damage. However, the sources of parechymal regeneration after hepatocellular liver injury still a matter of debate. Oliveira et al. (2), explained that oval cells can be either originated from BM-MSCs, or it is possible that oval cells increase in the replacement areas where fibrosis degradation occurs with functional parenchymatous cells after BM-MSC therapy. Moreover, Petersen et al. (22), put emphasis on the possibility that bone marrow may act, under certain physio-pathological conditions, as the progenitor of several types of liver cells. On the contrary, Vig et al. (28), stated that the contribution to liver regeneration from BM-derived cells was small, and liver regeneration occurs mainly through resident oval cells. Also, Elkhafif et al. (29), suggested that BM-MSCs may transdifferentiate into inflammatory cells, surrounding the granuloma, rather than into hepatic progenitor cells, presumably contributing to the host's reaction to the schistosomiasis infection. However, the exact characterization of this dif- 

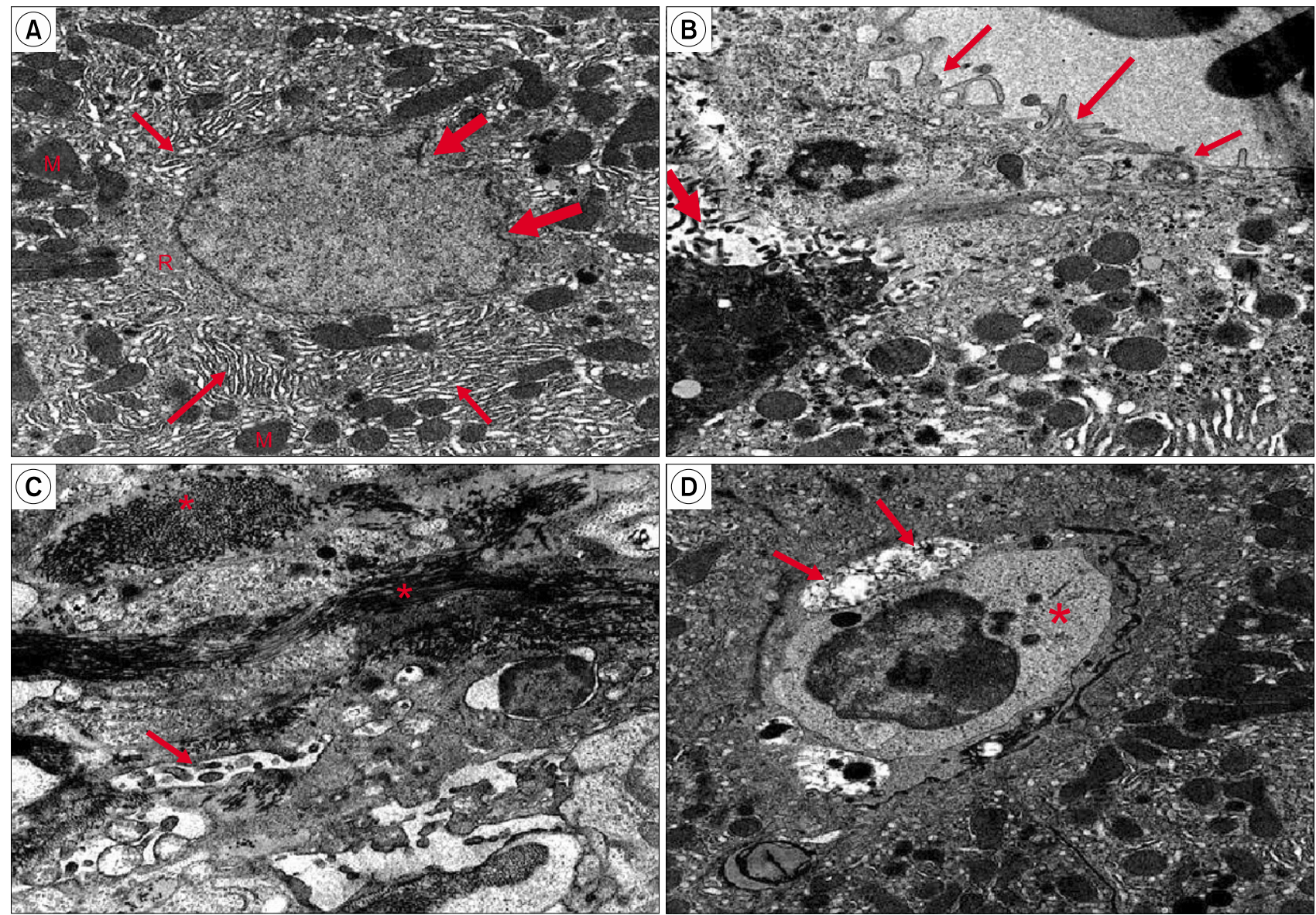

Fig. 7. (A) Show a large premature hepatocyte with signs of regeneration in the form of irregular nuclear membrane (thick arrow) and an apparent increase of organelles e.g. mitochondria $(M)$, rER $(\uparrow)$ and free ribosomes (R) (subgroup B2, TEM $\times 10000)$. (B) Show part of hepatocyte with few microvilli projecting from the surface facing the blood sinusoid ( $\uparrow$ ). A bile canaliculus appears in the form of its microvilli (thick $\uparrow$ ) nearly as the control group (Subgroup B2, TEM X10000). (C) Show damage to a bile canaliculus in the form of severe loss of its microvilli $(\uparrow)$. An apparent increase of collagen fibers appear in between necrotic hepatocytes $(*)$ (Subgroup B3, TEM $\times 10000$ ). (D) Show damage to a bile canaliculus in the form of partial loss of its microvilli $(\uparrow)$. HSCs $(*)$ are seen in the perisinusoidal space (Subgroup B3, TEM × 10000).

Table 1. Showing changes in area percentage of collagen, mean number of CK7 positive cells / high power field (HPFs) and circumference of the granuloma in different subgroups

\begin{tabular}{|c|c|c|c|c|}
\hline & Subgroup A2 & Subgroup B1 & Subgroup B2 & Subgroup B3 \\
\hline Area percentage of collagen fibers (\%) & $1.7 \pm .25(\boldsymbol{\sim} \mathbf{\Delta} \mathrm{O})$ & $15.61 \pm .81(* \mathbf{\Delta O})$ & $6.1 \pm 1.2(* \square 0)$ & $30.5 \pm 5,7(* \mathbf{\Delta})$ \\
\hline Circumference of granuloma & & $1.36 \pm 0.17(\mathbf{\Delta} \mathrm{O})$ & $1.02 \pm 0.016(-\mathrm{O})$ & $1.85 \pm 0.1(\mathbf{\Delta} \mathbf{\Delta})$ \\
\hline Number of CK7 / HPFs & $1.56 \pm 0.23(\boldsymbol{\Delta} \mathbf{\Delta} \mathrm{O})$ & $9.37 \pm 0.67(* \mathbf{\Delta})$ & $20.87 \pm 3.02(* \square \mathrm{O})$ & $8.87 \pm 2.06(* \mathbf{\Lambda})$ \\
\hline
\end{tabular}

*Significant difference from subgroup A2.

- Significant difference from Subgroup B1.

- Significant difference from Subgroup B3.

O Significant difference from Subgroup B3.

ferentiation remains to be carried out using panels of antibodies against several specific markers in a more extensive study.

\section{Conclusion}

In conclusion, our study showed that transplantation of BM-MSCs in mice with chronic liver disease caused by 
S. mansoni infection decreased liver fibrosis and contributed to an increase in oval cells as well as to the generation of new hepatocytes and/or to the improvement of resident hepatocytes.

Although there are still many unanswered questions regarding the mechanisms of action of transplanted cells in hepatic lesions in relation to the type and extent of liver injury, the timing of cell administration and the threshold number of transplanted cells are all important variables in the process of engraftment and differentiation that still need to be further defined.

\section{Recommendations}

Long-term experiments are recommended to allow an extensive follow-up of the engrafted cells to define their proper role and fate within the animal livers in different types of liver injury before future transplantation approaches can be successfully applied to the clinical application.

\section{Potential conflict of interest}

The authors have no conflicting financial interest.

\section{References}

1. Patz JA, Graczyk TK, Geller N, Vittor AY. Effects of environmental change on emerging parasitic diseases. Int $\mathrm{J}$ Parasitol 2000;30:1395-1405

2. Oliveira SA, Souza BS, Guimaraes-Ferreira CA, Barreto ES, Souza SC, Freitas LA, Ribeiro-Dos-Santos R, Soares MB. Therapy with bone marrow cells reduces liver alterations in mice chronically infected by Schistosoma mansoni. World J Gastroenterol 2008;14:5842-5850

3. Xiao SH, Mei JY, Jiao PY. Schistosoma japonicum-infected hamsters (Mesocricetus auratus) used as a model in experimental chemotherapy with praziquantel, artemether, and OZ compounds. Parasitol Res 2011;108:431-437

4. Ross AG, Bartley PB, Sleigh AC, Olds GR, Li Y, Williams GM, McManus DP. Schistosomiasis. N Engl J Med 2002;346:1212-1220

5. Xu H, Qian H, Zhu W, Zhang X, Yan Y, Mao F, Wang $\mathrm{M}, \mathrm{Xu} \mathrm{H}, \mathrm{Xu}$ W. Mesenchymal stem cells relieve fibrosis of Schistosoma japonicum-induced mouse liver injury. Exp Biol Med (Maywood) 2012;237:585-592

6. Lorenzini S, Gitto S, Grandini E, Andreone P, Bernardi M. Stem cells for end stage liver disease: how far have we got? World J Gastroenterol 2008;14:4593-4599

7. Salama H, Zekri AR, Bahnassy AA, Medhat E, Halim HA, Ahmed OS, Mohamed G, Al Alim SA, Sherif GM. Autologous CD34+ and CD133+ stem cells transplantation in patients with end stage liver disease. World J Gastroenterol

\section{0;16:5297-5305}

8. Ishii K, Yoshida Y, Akechi Y, Sakabe T, Nishio R, Ikeda R, Terabayashi K, Matsumi Y, Gonda K, Okamoto H, Takubo K, Tajima F, Tsuchiya H, Hoshikawa Y, Kurimasa A, Umezawa A, Shiota G. Hepatic differentiation of human bone marrow-derived mesenchymal stem cells by tetracycline-regulated hepatocyte nuclear factor 3beta. Hepatology 2008;48:597-606

9. Dominici M, Le Blanc K, Mueller I, Slaper-Cortenbach I, Marini F, Krause D, Deans R, Keating A, Prockop Dj, Horwitz E. Minimal criteria for defining multipotent mesenchymal stromal cells. The International Society for Cellular Therapy position statement. Cytotherapy 2006; 8:315-317

10. Horan PK, Melnicoff MJ, Jensen BD, Slezak SE. Fluorescent cell labeling for in vivo and in vitro cell tracking. Methods Cell Biol 1990;33:469-490

11. Boros DL. Immunopathology of Schistosoma mansoni infection. Clin Microbiol Rev 1989;2:250-269

12. Baddamwar A. Hepatic fibrosis in experimental Schistosoma japonicum infection in pigs: a histological and immunohistochemical study. Swedish University of Agriculture Sciences, Uppsala, Sweden. 2004; Report no. 46. ISSN; 1403-2201.

13. Ghanem LY, Dahmen U, Dirsch O, Nosseir MM, Mahmoud SS, Mansour WA. Does granulocyte-colony stimulating factor administration induce damage or repair response in schistosomiasis? World J Hepatol 2010;2:434-441

14. Herrera MB, Bussolati B, Bruno S, Morando L, MaurielloRomanazzi G, Sanavio F, Stamenkovic I, Biancone L, Camussi G. Exogenous mesenchymal stem cells localize to the kidney by means of CD44 following acute tubular injury. Kidney Int 2007;72:430-441

15. Gressner AM, Weiskirchen R, Breitkopf K, Dooley S. Roles of TGF-beta in hepatic fibrosis. Front Biosci 2002; 7:d793-d807.

16. Cho IJ, Kim YW, Han CY, Kim EH, Anderson RA, Lee YS, Lee CH, Hwang SJ, Kim SG. E-cadherin antagonizes transforming growth factor $\beta 1$ gene induction in hepatic stellate cells by inhibiting RhoA-dependent Smad3 phosphorylation. Hepatology 2010;52:2053-2064

17. Fang B, Shi M, Liao L, Yang S, Liu Y, Zhao RC. Systemic infusion of $\mathrm{FLK1}(+)$ mesenchymal stem cells ameliorate carbon tetrachloride-induced liver fibrosis in mice. Transplantation 2004;78:83-88

18. Rygiel KA, Robertson H, Marshall HL, Pekalski M, Zhao L, Booth TA, Jones DE, Burt AD, Kirby JA. Epithelialmesenchymal transition contributes to portal tract fibrogenesis during human chronic liver disease. Lab Invest 2008;88:112-123

19. Pulavendran S, Vignesh J, Rose C. Differential anti-inflammatory and anti-fibrotic activity of transplanted mesenchymal vs. hematopoietic stem cells in carbon tetrachloride-induced liver injury in mice. Int Immunopharmacol 2010;10:513-519

20. El-Mahdi MM, Mansour WA, Hammam O, Mehana NA, 
Hussein TM. Ameliorative effect of bone marrow-derived stem cells on injured liver of mice infected with Schistosoma mansoni. Korean J Parasitol 2014;52:151-162

21. Kordes C, Häussinger D. Hepatic stem cell niches. J Clin Invest 2013;123:1874-1880

22. Petersen BE, Bowen WC, Patrene KD, Mars WM, Sullivan AK, Murase N, Boggs SS, Greenberger JS, Goff JP. Bone marrow as a potential source of hepatic oval cells. Science 1999;284:1168-1170

23. Lenzi R, Liu MH, Tarsetti F, Slott PA, Alpini G, Zhai WR, Paronetto F, Lenzen R, Tavoloni N. Histogenesis of bile duct-like cells proliferating during ethionine hepatocarcinogenesis. Evidence for a biliary epithelial nature of oval cells. Lab Invest 1992;66:390-402

24. Song S, Witek RP, Lu Y, Choi YK, Zheng D, Jorgensen M, Li C, Flotte TR, Petersen BE. Ex vivo transduced liver progenitor cells as a platform for gene therapy in mice. Hepatology 2004;40:918-924

25. Theise ND, Saxena R, Portmann BC, Thung SN, Yee H,
Chiriboga L, Kumar A, Crawford JM. The canals of Hering and hepatic stem cells in humans. Hepatology 1999;30: 1425-1433

26. Novikoff PM, Yam A, Oikawa I. Blast-like cell compartment in carcinogen-induced proliferating bile ductules. Am J Pathol 1996;148:1473-1492

27. Yovchev MI, Grozdanov PN, Joseph B, Gupta S, Dabeva MD. Novel hepatic progenitor cell surface markers in the adult rat liver. Hepatology 2007;45:139-149

28. Vig P, Russo FP, Edwards RJ, Tadrous PJ, Wright NA, Thomas HC, Alison MR, Forbes SJ. The sources of parenchymal regeneration after chronic hepatocellular liver injury in mice. Hepatology 2006;43:316-324

29. Elkhafif N, Voss B, Hammam O, Yehia H, Mansy S, Akl M, Boehm S, Mahmoud S, El Bendary O, El Fandy G. Homing of transplanted bone marrow cells in livers of Schistosoma mansoni-infected mice. APMIS 2010;118: 277-287 